\title{
Measuring alcohol-based hand rub volume used by healthcare workers in practice
}

\author{
RA Leslie ${ }^{1 *}$, CJ Donskey ${ }^{2,3}$, TF Zabarsky ${ }^{3}$, AE Parker $^{4}$, DR Macinga $^{1}$, O Assadian ${ }^{5}$ \\ From 3rd International Conference on Prevention and Infection Control (ICPIC 2015) \\ Geneva, Switzerland. 16-19 June 2015
}

\section{Introduction}

Recent hand hygiene $(\mathrm{HH})$ research has focused largely on adherence to defined $\mathrm{HH}$ indications specified in global and national guidelines. Research focused on quality of $\mathrm{HH}$ events has been limited. A critical variable impacting the quality of hand disinfection is the volume of alcohol-based hand rub (ABHR) applied during a single $\mathrm{HH}$ event (i.e. application volume or AV). It may be assumed that healthcare workers (HCWs) use AVs recommended by manufacturers; however, HCWs typically are able to control AV. Manufacturer recommendations for AV of ABHR vary based on local requirements with typical recommendations varying from $1 \mathrm{~mL}$ to $5 \mathrm{~mL}$. To date, little data exists on actual ABHR AVs used in clinical practice.

\section{Objectives}

Determine the mean AVs of an ABHR used by HCWs during routine clinical practice.

\section{Methods}

Personal carriage bottles $(125 \mathrm{~mL})$ with lids engineered to count each ABHR use were used by 19 HCWs from five wards over three shifts in an acute care hospital. The bottles contained the WHO ethanol formulation. The mass of each bottle was measured before and after each shift and the number of uses was recorded after each shift. The total volume of ABHR used by each $\mathrm{HCW}$ during a shift was calculated by dividing the total mass used by the density of the product $(0.8607$ $\mathrm{g} / \mathrm{mL}$ ). The mean AV was determined by dividing the total volume by the number of ABHR uses recorded. Data was analyzed by ANOVA with nested random effects.

\section{Results}

The mean AV of ABHR used by each HCW per shift ranged from $0.27 \mathrm{~mL}$ to $1.61 \mathrm{~mL}$ per use. The overall mean AV was $0.73 \mathrm{~mL}( \pm 0.364 \mathrm{SD})$. The mean AVs were statistically significantly different among the five wards that participated ( $p=0.0118$ ). The number of $\mathrm{HH}$ events from personal carriage bottle per HCW over a shift ranged from 2 to 78 with a mean number of 22 (median 18).

\section{Conclusion}

The results of this study suggest that ABHR AVs used by HCWs are lower than manufacturer recommended volumes. Such practices may have a negative impact on ABHR effectiveness in clinical practice. More extensive studies are needed to understand whether the tendency to use AVs below recommended volumes is widespread, the factors influencing volume preference, and the impact of such practices on antimicrobial product effectiveness.

\section{Disclosure of interest}

None declared.

\section{Authors' details}

${ }^{1}$ Research and Development, GOJO Industries, USA. ${ }^{2}$ Case Western Reserve School of Medicine, USA. ${ }^{3}$ Cleveland Veterans Affairs Medical Center, USA. ${ }^{4}$ Center for Biofilm Engineering, Montana State University, USA. ${ }^{5}$ University of Huddersfield, UK.

Published: 16 June 2015

doi:10.1186/2047-2994-4-S1-P295

Cite this article as: Leslie et al:: Measuring alcohol-based hand rub volume used by healthcare workers in practice. Antimicrobial Resistance and Infection Control 2015 4(Suppl 1):P295.

${ }^{1}$ Research and Development, GOJO Industries, USA

Full list of author information is available at the end of the article 